\title{
Optimal medium use for continuous high density perfusion processes
}

\author{
Heino Büntemeyer, Claus Wallerius and Jürgen Lehmann \\ Institute for Cell Culture Technology, University of Bielefeld, P.O. Box 100131, 4800 Bielefeld 1, \\ Germany
}

Received 16 April 1992; accepted in revised form 24 August 1992

Key words: hybridoma growth, medium use, re-use, inhibition, toxic metabolites, continuous medium recycling

\begin{abstract}
For maintenance of high cell density in continuous perfusion processes not only feeding with substrates but also removal of inhibitors and toxic waste products are of special interest. High perfusion rates cause large volumes of product containing medium which have to be processed in product isolation. In order to minimize these volumes concentrated feed solutions of optimized medium are used. On the other hand, such media may cause high concentrations of toxic or inhibitory metabolites which can negatively influence cell growth and product formation. Especially, if the spent medium (or special parts of it) is used again after product isolation, the removal or even better the control of inhibitor production is of highest importance. We have developed a continuous fermentation concept and system (continuous medium cycle bioreactor, cMCB) in which both limitation and inhibition effects can be generated to identify special substances as limiting or inhibitory components. With the results from those experiments it was possible to lower the total perfusion rate during serum-free perfusion cultures of hybridoma cells and to obtain an optimal substrate utilization. The advantages for decreasing the production costs (for media, special supplements and product isolation) are obvious. The other aim of this study was to identify secreted metabolic waste products as inhibitor or toxic metabolite.
\end{abstract}

\section{Introduction}

Cell culture medium is one of the most expensive aspects of the production of mammalian cell products. Not all the nutrients contained in these media can be used because, depending on cell type and cell density, some specific components tend to reach limitation relatively quickly. If high nutrient concentrations are used in continuous processes (perfusion systems), toxic and inhibitory substances are produced in high concentrations. To avoid this problem in most cases high dilution rates are used. On the other hand, this generates greater volumes of culture fluids and lower product concentrations.

The major advantage of medium re-use is a better process economy (Lehmann et al., 1990) because of higher product concentrations in smaller process and media volumes. Low protein or protein-free media are useable for almost all cell lines and the re-use of catalytic medium compounds and cell derived autocrine factors is achieved. The main disadvantage in this concept is the accumulation of inhibitors and toxic meta- 
bolites in the medium and, probably, a low product stability or degradation because of increasing enzyme activity.

Therefore, the aims of this study are the optimization of medium use (re-use and recycling of unexhausted medium components), the minimization of perfusion rates and the identification of inhibitors and toxic waste products. To generate defined limitation and inhibition states it is necessary to decouple nutrient supply and inhibitor accumulation at constant cell densities in a continuous cultivation procedure. To realize this a bioreactor concept was developed where several fluid streams are connected to the bioreactor vessel to control cell removal, waste removal, medium recycling and nutrient supply.

The concept of this bioreactor setup is compar- able to a stirred tank dialysis system. The main differences are continuous feeding of concentrated nutrient solution and the type of the internal perfusion membrane, which is not a dialysis membrane but a microfiltration membrane.

\section{Materials and methods}

\section{Bioreactor concept}

The bioreactor system used in this study was a 2 litre bench scale perfusion system based on a modified BIOSTAT BF2 bioreactor (B. Braun Biotech International, Melsungen, Germany).

The reactor was equipped with an internal hollow fibre microfiltration membrane $(2 \mathrm{~m} / 1=$

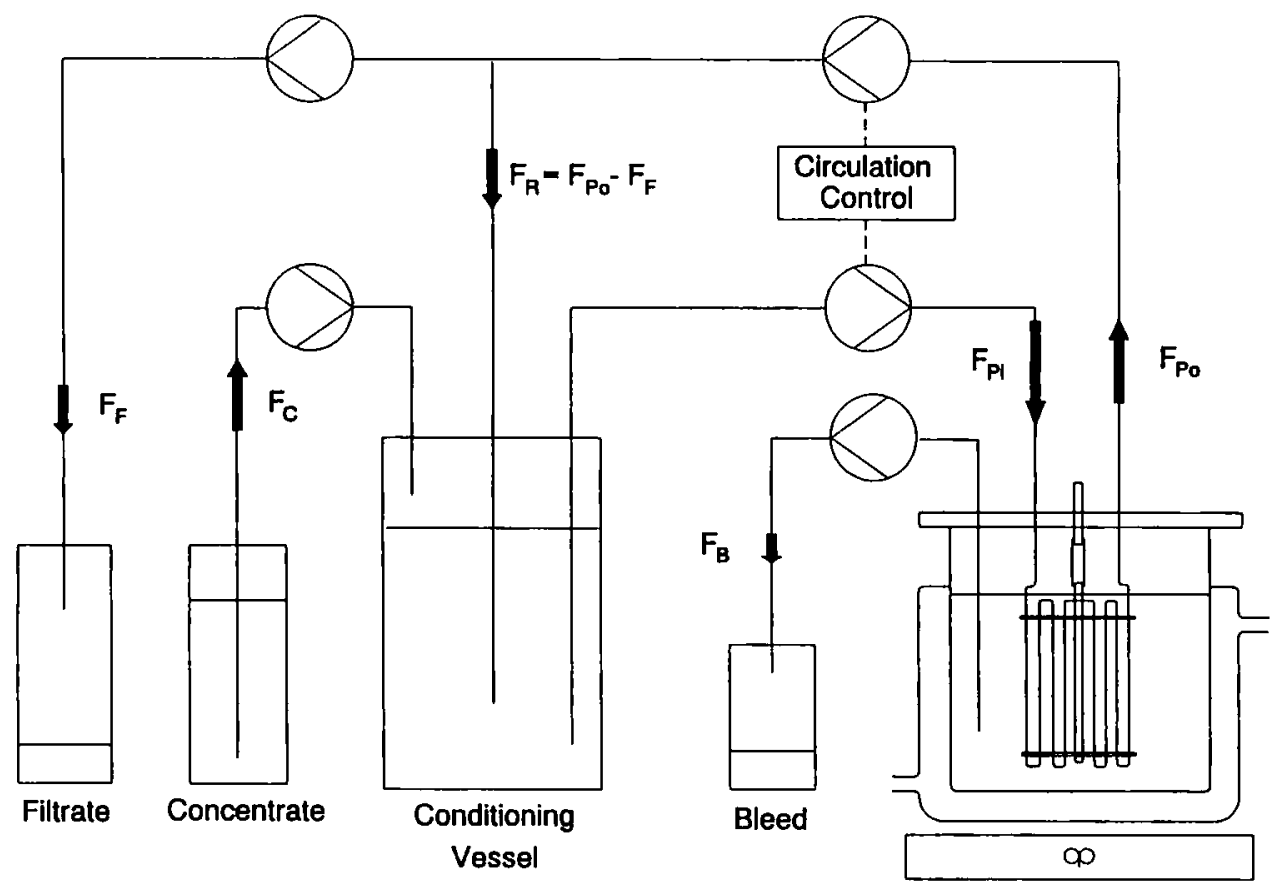

Fig. I. Flow scheme of continuous Medium Cycle Bioreactor (cMCB). The aeration system based on bubble free membrane aeration is not shown in this scheme and described elsewhere (Lehmann, 1988).

Definition of flow parameter in Fig. 1.
Concentrate feed
$\mathrm{F}_{\mathrm{C}}=\mathrm{F}_{\mathrm{B}}+\mathrm{F}_{\mathrm{F}}$
Recycling
Filtrate rate
Bleed rate
$D_{B}=F_{B} / V_{R}$
Circulation rate
$D_{\mathrm{P}}=\mathrm{F}_{\mathrm{PO}} / \mathrm{V}_{\mathrm{R}}$
Reactor volume
$\mathrm{V}_{\mathrm{R}}(\mathrm{L})$
Dilution rate
$\mathrm{D}=\mathrm{F}_{\mathrm{C}} / \mathrm{V}_{\mathrm{R}}=\left(\mathrm{F}_{\mathrm{F}}+\mathrm{F}_{\mathrm{B}}\right) / \mathrm{V}_{\mathrm{R}}$
$F_{R}=F_{P O}-F_{F}$
$D_{F}=F_{F} / V_{R}$

Flow rate

$F(\mathrm{~L} / \mathrm{d})$

Indices: $\mathrm{B}=\mathrm{Bleed} ; \mathrm{C}=$ Concentrate $; \mathrm{F}=$ Filtrate; $\mathrm{Pi}=$ Perfusion inlet $\mathrm{Po}=$ Perfusion outlet. 
$\left.163 \mathrm{~cm}^{2} / 1\right)$ which retains only cells and particles $(0.3 \mu \mathrm{m})$. Soluble substances can pass the membrane unhindered. This membrane was connected at each end via a peristaltic pump (Watson-Marlow 501-UR) to a conditioning vessel (total volume $5 \mathrm{l}$ ). From this vessel medium was cycled through the reactor in the following way. In a cycle of feeding and harvesting, first, the harvesting pump ran for 25 minutes with a low pump rate (transmembrane flux $3 \mathrm{l} / \mathrm{m}^{2} \cdot \mathrm{h}$ ) followed by a 5 min period for feeding with high pump rate (transmembrane flux $40 \mathrm{l} / \mathrm{m}^{2} \cdot \mathrm{h}$ ). This special backflushing procedure prevented the microfiltration membrane from early clogging (Büntemeyer et al., 1987). Conditioning in this vessel is achieved by feeding with concentrated nutrient solution and removing of filtrate as described in Fig. 1. This system is called CONTINUOUS MEDIUM CYCLE BIOREACTOR (cMCB) in contrast to the procedure described by Kempken et al. (1991). Additionally, a bleed stream was connected direct to the bioreactor to control cell density and maintain steady state conditions.

The bioreactor was aerated with a hydrophobic hollow fibre membrane $\left(3 \mathrm{~m} / \mathrm{l}=245 \mathrm{~cm}^{2} / \mathrm{l}\right)$ (Lehmann et al., 1988) connected to a 4-channelmass-flow-controller (MKS Instruments, München, Germany) for air, $\mathrm{O}_{2}, \mathrm{~N}_{2}$ and $\mathrm{CO}_{2}$ guided by a personal computer depending on state values of $\mathrm{pO}_{2}$ and $\mathrm{pH}$. Temperature was set to $37^{\circ} \mathrm{C}, \mathrm{pH}$ to 7.2 and $\mathrm{pO}_{2}$ to $40 \%$ air saturation.

\section{Cells}

The cell line used in this study was the hybridoma HB 58 (ATCC). This cell is a rat mouse hybridoma which produces rat antibodies type $\operatorname{IgG}_{1}$, specific for mouse $\kappa$ light chain. Cell numbers were determined microscopically by trypan blue exclusion.

\section{Medium}

The medium used for all experiments was a serum-free low protein medium (SF-medium) consisting of a 1:1 mixture of DMEM and F12 (Gibco, Eggenstein, Germany). The following supplements were used per litre medium: $10 \mathrm{mg}$ Transferrin (Fe saturated), $10 \mathrm{mg}$ Insulin, 50 $\mu \mathrm{mol}$ Ethanolamin, $2 \mathrm{mmol}$ Glutamine, $2 \mathrm{mmol}$ sodium pyruvate, $20 \mathrm{nmol} \mathrm{SeO}$ and $2 \mathrm{ml} \mathrm{Lipo-}$ proteins (ExCyte, Bayer Diagnostics, München, Germany). As nutrient concentrate the complete serum-free medium was used, supplemented per litre with $5.55 \mathrm{mmol}(1 \mathrm{~g})$ glucose, $50 \mu \mathrm{mol}$ Ethanolamin, 2 mmol sodium pyruvate and various concentrations of amino acids and glutamine depending on the demand of the cells at high cell density in perfusion mode. In Table 1 the additional components for the nutrient concentrate are given. These values are calculated from intensive studies of nutrient utilization of this cell line at various cultivation conditions including high cell density perfusion experiments.

\section{Analytical methods}

Free amino acids were analyzed using an automated reversed phase high performance liquid

Table 1. Substrate concentrations in nutrient concentrate used for all cMCB experiments in this study

\begin{tabular}{lr}
\hline Substrate & $\mu \mathrm{mol} / 1$ \\
\hline Alanine & 50 \\
Arginine & 1500 \\
Asparagine & 117 \\
Aspartatic acid & 110 \\
Cysteine & 100 \\
Cystine & 217 \\
Glutamine & 11240 \\
Glutamic acid & 50 \\
Glycine & 383 \\
Histidine & 207 \\
Isoleucine & 812 \\
Leucine & 908 \\
Lysine & 1498 \\
Methionine & 498 \\
Phenylalanine & 672 \\
Proline & 223 \\
Serine & 393 \\
Threonine & 1290 \\
Tryptophane & 93 \\
Tyrosine & 245 \\
Valine & 501 \\
Glucose & 23055 \\
\hline
\end{tabular}


chromatographic system (RP-HPLC) (Kontron D450-MT2, Eching, Germany) with precolumn derivatization using the OPA method as described previously (Büntemeyer et al., 1991). Glucose and lactate concentrations were analyzed using an automatic analyzer system based on enzymatic and electrochemical reactions (YSI 2700, Yellow Springs Instruments, $\mathrm{OH}$, USA). Ammonia was measured with a gas sensitive electrode (NH500/ 2 pMX2000/ION, WTW, Weilheim, Germany). Antibody concentrations in the supernatant were analyzed either by a kinetic sandwich ELISA method (Büntemeyer et al., 1991) or with the ABICAP-System (ABION, Benediktbeuren, Germany).

\section{Results}

In Fig. 2 the first experiment with continuous MCB setup (Fig. 1) is shown. The conditioning vessel was filled with 21 of fresh SF-medium. Cell inoculum was prepared in T-flasks. The initial density was $1.5 \cdot 10^{5}$ viable cells $/ \mathrm{ml}$. After inoculation the cells started to grow without a lag period. One day later the continuous cycle mode was started with following rates: filtrate rate $F_{F} / V_{R}=0.3 d^{-1}$, bleed rate $F_{B} / V_{R}=0.12 d^{-1}$, recycling rate $F_{R} / N_{R}=0.7 d^{-1}$, circulation rate

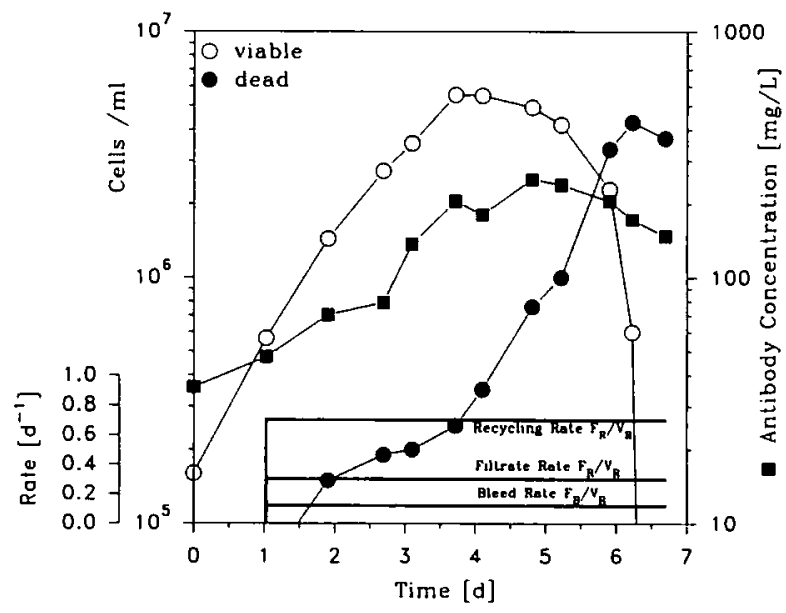

Fig. 2. Experiment 1 in cMCB (ref. Fig. 1). Shown are viable and dead cell densities, antibody concentration in the bioreactor and the performed flow rates.
$\mathrm{F}_{\mathrm{Po}} / \mathrm{V}_{\mathrm{R}}=1.0 \mathrm{~d}^{-1}$. Two days later the cells reached a final viable cell density of $5.5 \cdot 10^{6}$ cells $/ \mathrm{ml}$. At that time no limitation of any essential nutrient like glucose, glutamine and other essential amino acids occurred (Fig. 4). After a one day stationary phase the cells died completely in less than 2 days. From Fig. 3 it can be seen that concentrations of the major waste products, lactate and ammonium, did not reach values above $1.5 \mathrm{~g} / 1$ (16 $\mathrm{mM}$ ) and $130 \mathrm{mg} / 1(7.2 \mathrm{mM})$, respectively. From previous chemostat experiments with various concentrations of lactate and ammonium using the same cell line (data not shown) it was known that these concentrations would not affect the cells in that negative way. Therefore, other unknown toxic products might be accumulated in the system very fast and cause this rapid cell death.

For the first approach to identify the unknown toxic products the reactor setup was modified (Fig. 5). An ultrafiltration hollow fibre module (Bioran, Schott, Germany, cutoff $10 \mathrm{kDa}$ ) was fitted into the circulation stream in such a way that the high molecular weight (HMW) components are retained in the inner cycle. Only ultrafiltrate $(<10 \mathrm{kDa})$ can leave the system. If the effect in the first experiment is caused by cell derived HMW substances they should accumulate faster in this modified system and cause an earlier cell

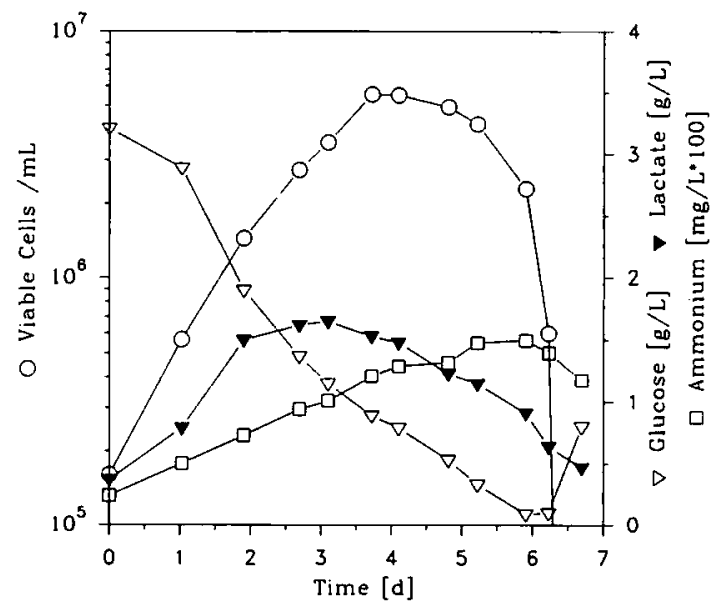

Fig. 3. Substrate and waste product concentrations during cMCB experiment 1 (ref. Fig. 2). 

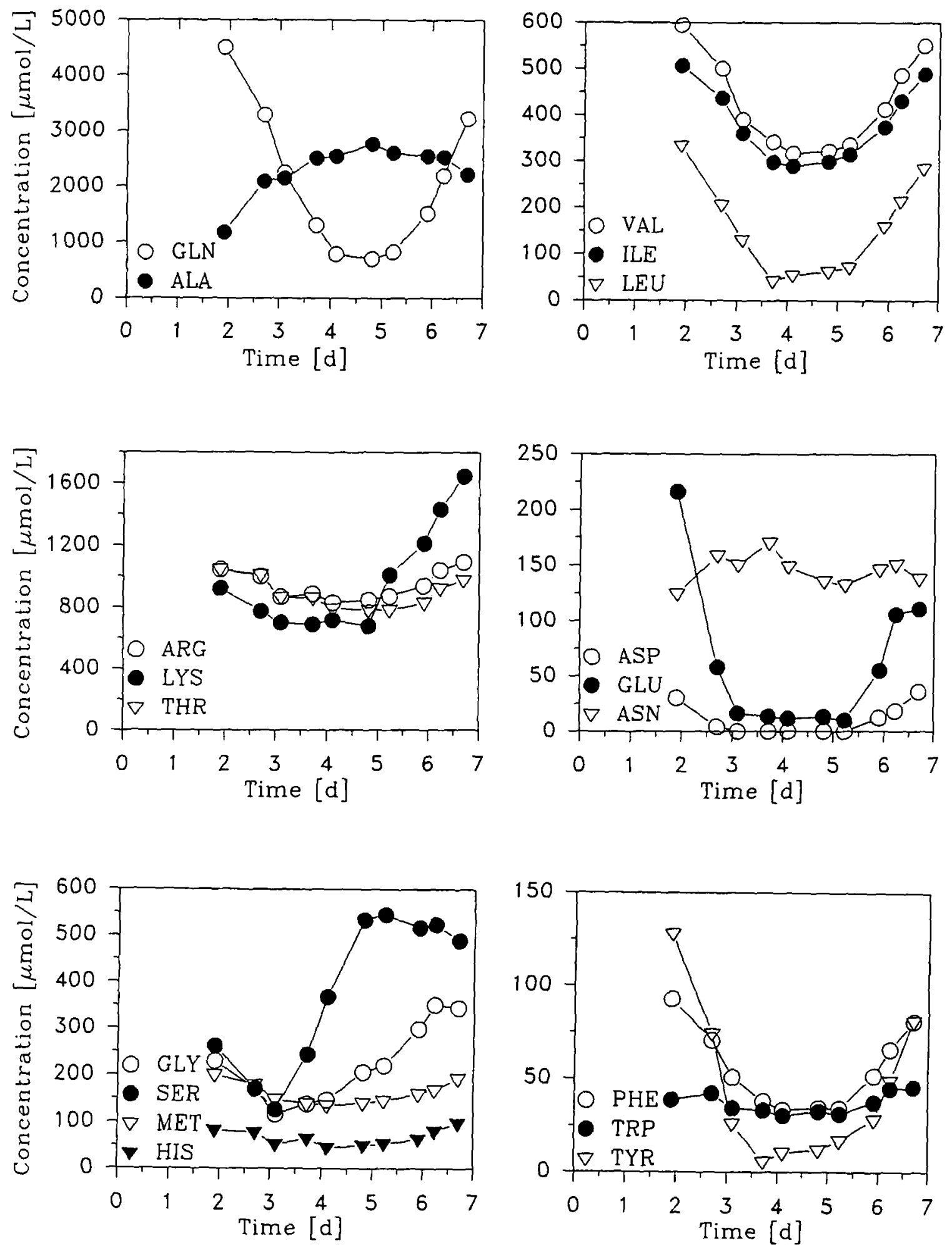

Fig. 4. Amino acid concentrations in the bioreactor during $\mathrm{CMCB}$ experiment 1. 


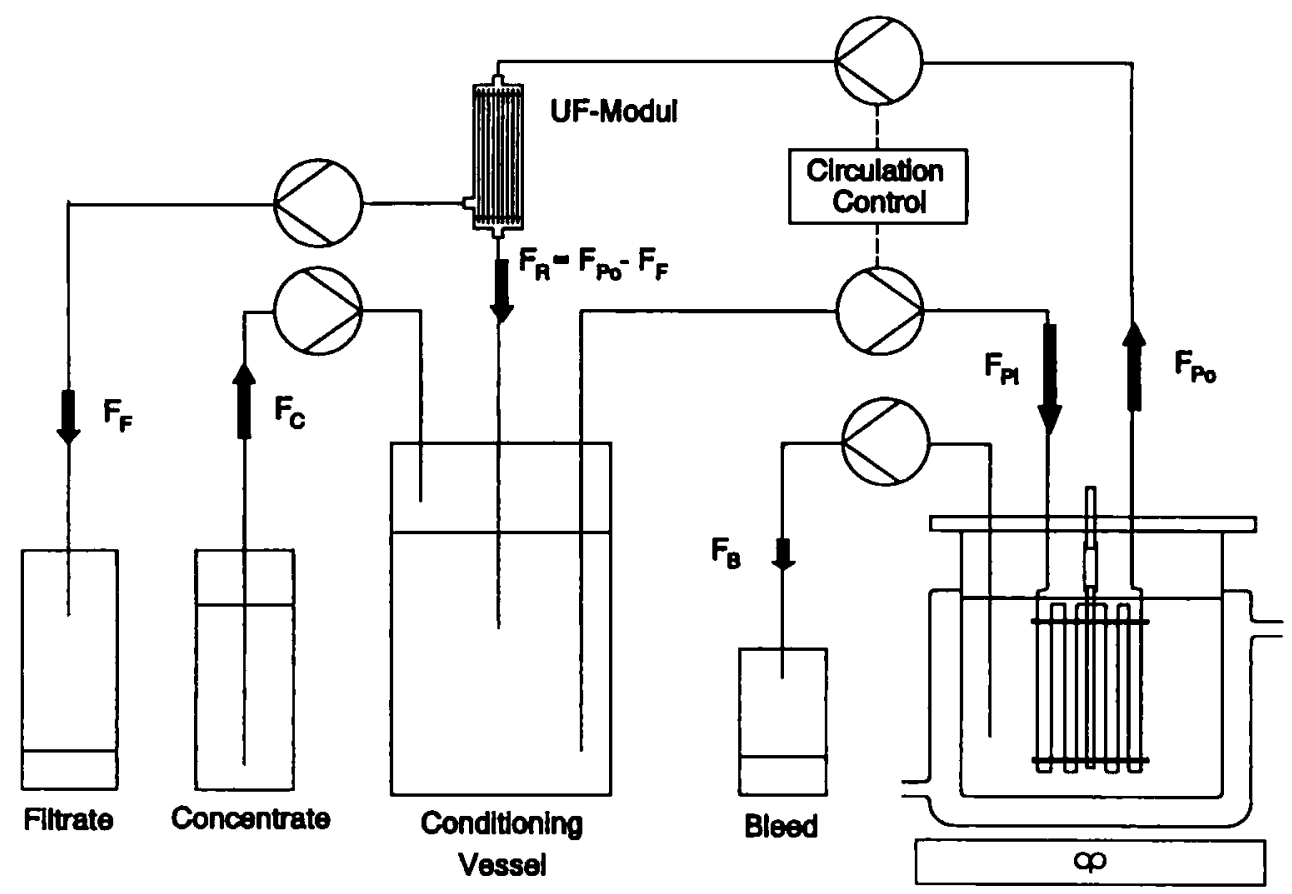

Fig. 5. Flow scheme of Continuous Medium Cycle Bioreactor with total recycling of high molecular weight components (inserted UF module).

death. In Fig. 6 the result of that experiment is shown. After an initial lag period of one day the cells started to grow with a growth rate comparable to experiment 1 . After a 2 day batch phase with exponential growth continuous mode was

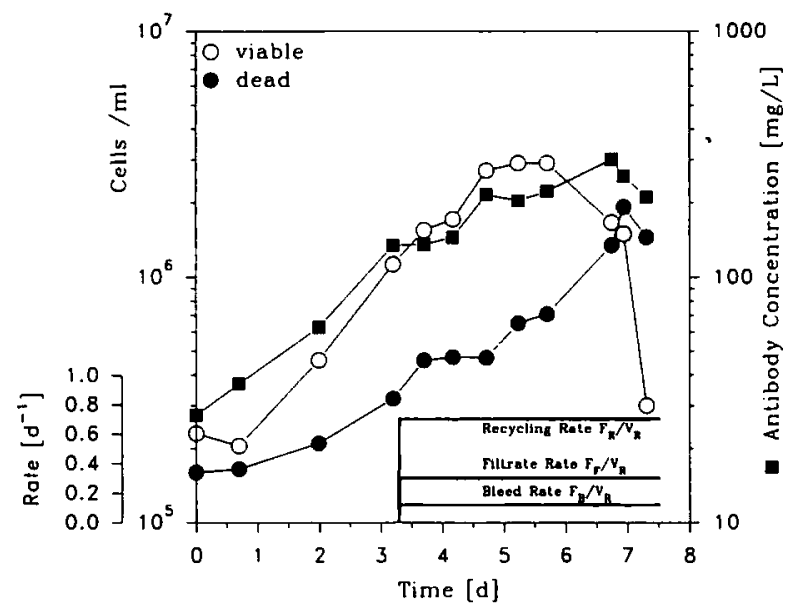

Fig. 6. cMCB experiment 2 with inserted ultrafiltration module (total recycling of high molecular weight components, ref. Fig. 5). activated with the same flow rates as in the first experiment. One day later the cells reached the final viable cell density of $2.9 \cdot 10^{6} \mathrm{cells} / \mathrm{ml}$ followed by another day in stationary phase. Thereafter the dramatic cell death occurred again. Fig-

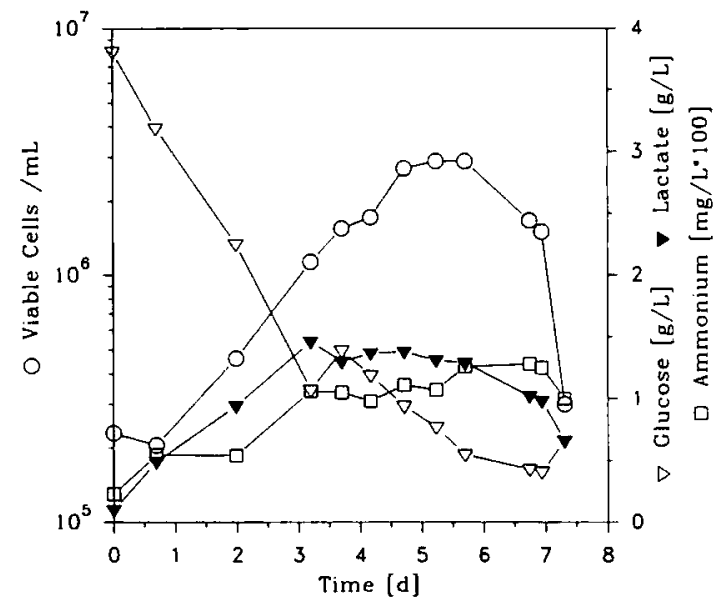

Fig. 7. Substrate and waste product concentrations during cMCB experiment 2 (ref. Fig. 6). 
ure 7 illustrates that the concentrations of the waste products lactate and ammonium reached nearly the same maximum concentrations during the stationary phase as in experiment 1 (Fig. 3). As in experiment 1 nutrients were not limiting (data not shown).

The shapes of the growth curves in both experiments are very similar with short stationary phases and dramatic death phases. A normalized projection of growth curve of experiment 1 onto growth curve of experiment 2 show exactly the same time course for stationary and death phase. This leads to the assumption that first low molecular weight components cause cell death before high molecular weight substances can accumulate to concentrations which will affect the cells. Due to the cut off of the utilized ultrafiltration membrane these toxic substances have a molecular weight below $10 \mathrm{kDa}$.

With the results of these two short-term recycling fermentations a strategy for long-term cultivation was designed. The aim was the maintenance of a stable steady state with a minimal total perfusion rate. The bioreactor setup was the same as for experiment 1 . In this case the conditioning vessel was filled with 4 I SF-medium.

Figure 8 shows the time course of the longterm experiment with the hybridoma cell line $\mathrm{HB}$ 58. This experiment is divided into 6 sections. In the first segment the cells were grown in batch and simple perfusion mode reaching a viable cell density of $2.7 \cdot 10^{6}$ cells $/ \mathrm{ml}$. From day 3 on the circulation rate was kept constant at a rate of $F_{\mathrm{Po}} / V_{\mathrm{R}}=1.0 \mathrm{~d}^{-1}$ for the rest of the experiment. In the second part the cell bleed stream was activated and maintained at a constant rate of $F_{B} / V_{R}=$ $0.1 \mathrm{~d}^{-1}$ for the whole experiment. After a short growth period the viable cell density decreased indicating limitation or inhibition. To stop this decrease in viability the filtrate removal was started at a flow rate of $F_{F} / V_{R}=0.1 d^{-1}$ resulting in a stabilized viability (section 3 ). An increase in filtrate rate $\left(F_{F} / V_{R}=0.2 d^{-1}\right)$ (section 4) resulted in both increasing viability and cell density which stabilized at approx. $4 \cdot 10^{6}$ viable cells $/ \mathrm{ml}$.

To determine whether limitation or inhibition effects influenced cell viability in section 2 , an ultrafiltrated (cut off $10 \mathrm{kDa}$ ) and resupplemented filtrate from sections 3 and 4 was used in segment 5 as concentrated feed solution (concentrations

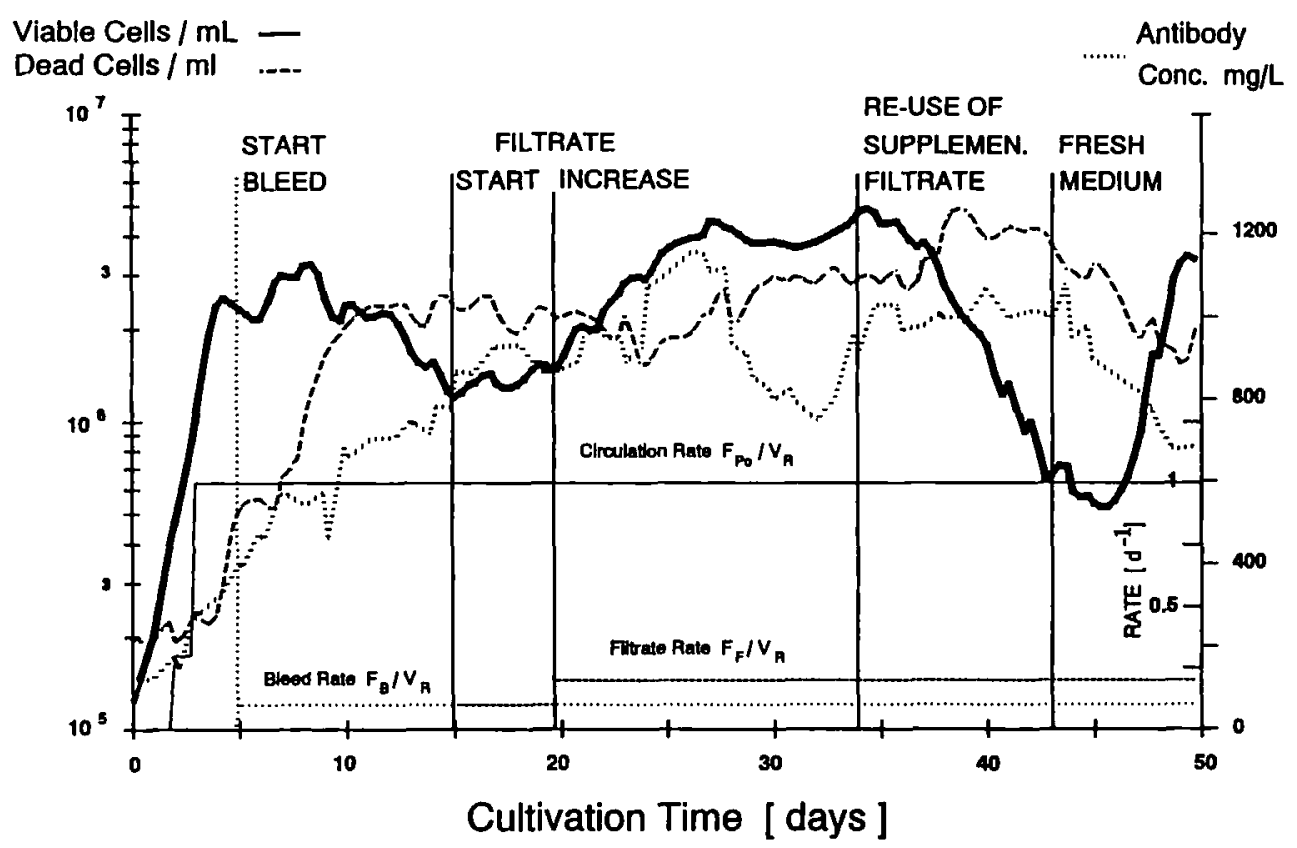

Fig. 8. Long-term cultivation of hydridoma HB 58 in $\mathrm{CMCB}$ experiment 2 (ref. Fig. 6). 
for all components same as for fresh concentrate used before). Because of twice the bioreactor volume in the conditioning vessel the effect delayed for 4 days but resulted finally also in cell death. During this period (day 35-40) all amino acid concentrations and glucose concentration (data not shown) raised implying that a limitation was unlikely.

This breakdown was stopped by using fresh concentrate in section 6 . Cell density and viability were recovered in a few days. During all sections glucose concentration never dropped below 0.5 $\mathrm{g} / \mathrm{l}(2.5 \mathrm{mM})$, lactate and ammonium concentrations always were below $1.7 \mathrm{~g} / \mathrm{l}(18.8 \mathrm{mM})$ and $150 \mathrm{mg} / \mathrm{l}(8 \mathrm{mM})$, respectively.

\section{Discussion}

The results show that in continuous perfusion cultures not only limitation but also inhibition and toxic effects may contribute to cell death. A stable steady state can be maintained if a minimal total feed rate with concentrated feed medium is used (in this experiment $D=0.3 \mathrm{~d}^{-1} ; D_{F}=0.1 \mathrm{~d}^{-1}$ for cell bleed and $D_{F}=0.2 d^{-1}$ for filtrate removal). This results in a much better use of all medium resources and higher product concentration. The flow rate of the filtrate stream responsible for removal of toxic substances is strongly depending on metabolic activity of the cells and nutrient concentration in the concentrate stream.

From section 4 (Fig. 8) it is obvious that a total re-use of an ultrafiltrated and resupplemented waste medium (filtrate) is not suitable without prior detoxification steps (to be developed for known and unknown toxic/inhibitory substances). But $60-70 \%$ of feeding medium (fresh medium) can be resupplemented and recycled for a better use of all medium resources and re-use of catalytic and autocrine factors (overall dilution rate $\mathrm{D}=$ $\left.0.3 \mathrm{~d}^{-1}\right)$.

We conclude that low molecular weight substances may accumulate much more or may be much more toxic than high molecular weight compounds. These results are in good agreement with the investigations of Rønning et al., (1990,
1991) who found inhibitory/toxic effects in the LMW area.

Inhibitors and/or toxic components are smaller than $10 \mathrm{kDa}$ because of the cut off of the inserted UF module (Fig. 6). It was reported by Newland et al. (1990), Ozturk et al. (1992) and others that especially ammonia can have growth inhibiting effect on hybridoma growth. But our control experiments with various concentrations of ammonia and lactate did not show these dramatic effects on total cell death in a day.

Therefore, other still unknown substances are produced by hybridomas which are of low molecular weight and accumulate to very effective concentrations during medium recycling. The next task will be identification of these substances.

\section{Acknowledgement}

This work was partly supported by the project "Development of a procedure and a plant for the recirculation of nutrient media for animal cell culture" (BMFT ref. no. 0319346A) of the German Ministry of Research and Technology. We thank Ms. A. Stenner and Mr. R. Seutter for their excellent technical assistance.

\section{References}

Büntemeyer H, Bödeker BGD and Lehmann J (1987) Membrane-stirrer-reactor for bubble free aeration and perfusion. In: Modem approaches to animal cell technology, Spier RE and Griffiths JB (eds), Butterworth, London, pp. 411-419.

Büntemeyer H, Lütkemeyer D and Lehmann J (1991) Optimization of serum-free processes for antibody production. Cytotechnology 5: 57-67.

Kempken R, Büntemeyer $H$ and Lehmann J (1992) The medium cycle bioreactor $(\mathrm{MCB})$ : Monoclonal antibody production in a new economic production system. Cytotechnology 7: 63-74.

Lehmann J, Vorlop J and Büntemeyer H (1988) Bubble free reactors and their development for continuous culture with cell recycle. In: Animal cell biotechnology 3, Spier RE and Griffiths JB (eds), Academic Press, London, pp. 221-237.

Lehmann J, Kempken R, Lütkemeyer D and Büntemeyer $H$ (1990) Economic aspects of medium recycling. In: Trends in Animal Cell Culture Technology, Murakami H (ed), $\mathrm{VCH}$ Publishers, pp. 55-59. 
Newland M, Greenfield PF and Reid S (1990) Hybridoma growth limitations: The roles of energy metabolism and ammonia production. Cytotechnology 3: 215-229.

Ozturk SS, Riley MR and Palsson BO (1992) Effects of ammonia and lactate on hybridoma growth, metabolism and antibody production. Biotech. Bioeng. 39: 418-431.

Rønning OW and Schartum 'M (1990) Removal of inhibitory factors from hybridoma cell cultures by gel filtration. In: Production of Biologicals from Animal Cells in Culture, Spier
RE, Griffiths JB and Meignier B (eds), Butterworth, London, pp. 218-223.

Rønning OW, Schartum M, Winsnes A and Lindberg G (1991) Growth limitation in hybridoma cell cultures: The role of inhibitory or toxic metabolites. Cytotechnology 7: 15-24.

Address for offprints: Heino Büntemeyer, Institute for Cell Culture Technology, University of Bielefeld, P.O. Box 100131, 4800 Bielefeld 1, Germany. 